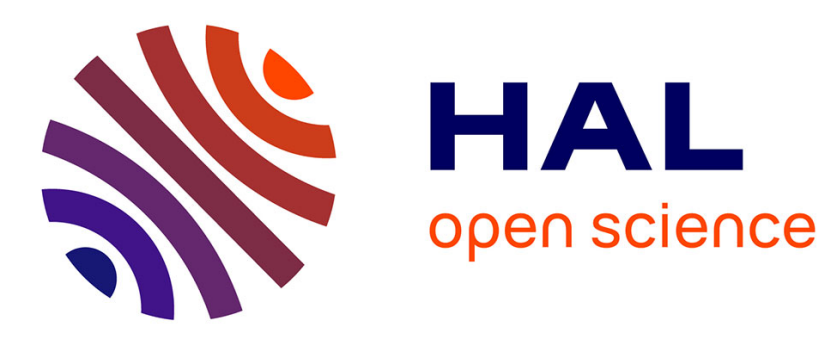

\title{
Solubility of eflucimibe in supercritical carbon dioxide with or without a co-solvent
}

\author{
Martial Sauceau, Jean-jacques Letourneau, Bernard Freiss, Dominique \\ Richon, Jacques Fages
}

\section{To cite this version:}

Martial Sauceau, Jean-jacques Letourneau, Bernard Freiss, Dominique Richon, Jacques Fages. Solubility of eflucimibe in supercritical carbon dioxide with or without a co-solvent. Journal of Supercritical Fluids, 2004, 31 (2), pp.133-140. 10.1016/j.supflu.2003.11.004 . hal-01668424

HAL Id: hal-01668424

https://hal.science/hal-01668424

Submitted on 15 Mar 2018

HAL is a multi-disciplinary open access archive for the deposit and dissemination of scientific research documents, whether they are published or not. The documents may come from teaching and research institutions in France or abroad, or from public or private research centers.
L'archive ouverte pluridisciplinaire HAL, est destinée au dépôt et à la diffusion de documents scientifiques de niveau recherche, publiés ou non, émanant des établissements d'enseignement et de recherche français ou étrangers, des laboratoires publics ou privés. 


\title{
Solubility of eflucimibe in supercritical carbon dioxide with or without a co-solvent
}

\author{
M. Sauceau ${ }^{\text {a }}$, J.-J. Letourneau ${ }^{\text {a }}$, B. Freiss ${ }^{b}$, D. Richon ${ }^{\text {c }}$, J. Fages $^{\text {a,* }}$ \\ ${ }^{a}$ Laboratoire de Génie des Procédés des Solides Divisés, UMR CNRS 2392, École des Mines d'Albi-Carmaux, 81013 Albi, France \\ b Institut de Recherche Pierre Fabre, 81603 Gaillac, France \\ ${ }^{\mathrm{c}}$ Laboratoire de Thermodynamique des Équilibres entre Phases/CENERG, École des Mines de Paris, 77305 Fontainebleau, France
}

\begin{abstract}
Eflucimibe is a drug, which displays hypocholesterolemic and anti-atherosclerotic properties in animal models. The solubility of eflucimibe in supercritical carbon dioxide has been investigated with an apparatus based on an analytical open circuit method. Solubility values have been measured at 308.15 and $318.15 \mathrm{~K}$ in the pressure range $8-30 \mathrm{MPa}$. Solubility appears to be an increasing function of both temperature and pressure. The two co-solvents investigated, ethanol and dimethylsulphoxide, are found to significantly enhance the solubility. Solubility data are reported for the $308.15 \mathrm{~K}$ isotherm at different total pressures and different solvent/co-solvent ratios. The observed co-solvent effects can be explained not only by density effects, but by the effect of molecular interactions on the basis of compound solubility parameters.
\end{abstract}

Keywords: Eflucimibe solubility; Supercritical carbon dioxide; Co-solvent effect; Specific interactions

\section{Introduction}

Particle generation processes using supercritical fluids (SCF) lead to fine and monodisperse powders in mild operating conditions [1]. The SCF can be used either as a solvent as in the rapid expansion of a supercritical solution (RESS) process or as an anti-solvent as in the supercritical anti-solvent (SAS) process.

The interest in using this technology lies in the superior properties inherent to this class of fluid, including the ability to vary solvent density in large extents

\footnotetext{
* Corresponding author. Tel.: +33-5-63-49-31-41; fax: +33-5-63-49-30-25.

E-mail address: jacques.fages@enstimac.fr (J. Fages).
}

and solvent properties by changing either the applied pressure or temperature. The viscosity of a SCF is much lower than that of a liquid, and its diffusivity is found to be between that of a gas and of a liquid.

Carbon dioxide $\left(\mathrm{CO}_{2}\right)$ is the most common SCF, mainly because it is easy to handle, it is inert, non-toxic, non-flammable, and has convenient critical co-ordinates. However, it has limitations resulting from its lack of polarity and associated lack of capacity for specific solvent-solute interactions. For most high molecular weight compounds (non-volatile organic compounds), the solubility in supercritical $\mathrm{CO}_{2}$ is quite low requiring high temperatures and pressures for substantial loadings. Thus, there is a great incentive to improve solvent polarity. For these 


\begin{tabular}{|ll|}
\hline \multicolumn{2}{|l|}{ Nomenclature } \\
$A_{\mathrm{c}}$ & co-solvent effect \\
$A_{\mathrm{c} \rho}$ & co-solvent density effect \\
$C$ & concentration $\left(\mathrm{kg} \mathrm{m}^{-3}\right)$ \\
EoS & equation of state \\
$k_{i j}$ & binary interaction parameter \\
$l_{i j}$ & binary interaction parameter \\
$P$ & pressure (MPa) \\
$T$ & temperature $(\mathrm{K})$ \\
$y$ & mole fraction \\
$\rho$ & density $\left(\mathrm{kg} \mathrm{m}^{-3}\right)$ \\
& \\
Subscripts \\
1 & main solvent component (carbon dioxide) \\
2 & solute component (solid) \\
3 & co-solvent \\
\hline
\end{tabular}

purposes, small amounts of a highly polar co-solvent can be added to $\mathrm{CO}_{2}$ in order to increase its solvating power. Progress has been made towards the understanding of the interactions involved in dilute supercritical mixtures. It has been shown that near the critical point of a SCF solution, the solvent molecules form "clusters" around the large solute molecules to form a local density that is higher than the bulk density $[2,3]$. When a co-solvent is added, the situation is further complicated by the differences in local and bulk compositions $[4,5]$.

To develop supercritical processing of a given product, its solubility in the selected medium is a key parameter. Unfortunately, this quantity is frequently unknown and requires experimental determination. An apparatus, based on an open circuit method [6], has therefore been developed to carry out accurate measurements of low solute solubilities in pure and mixed supercritical solvents.

In this work, this apparatus has been used to study the solubility of eflucimibe in supercritical fluids. Eflucimibe ( $S$-enantiomer of $2^{\prime}, 3^{\prime}, 5^{\prime}$-trimethyl-4'-hydroxy$\alpha$-dodecylthio-phenylacetanilide) is a drug inhibiting acyl-coenzyme A:cholesterol acyltransferase (ACAT), an enzyme which inhibition may lead to lower serum cholesterol concentration [7]. Hypocholesterolemic properties of eflucimibe have been demonstrated on rabbits and this molecule is therefore a good candi-

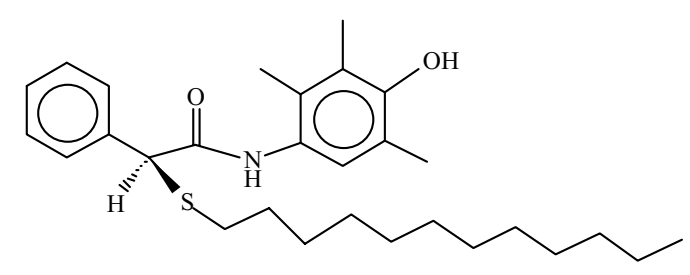

Fig. 1. Formula of eflucimibe.

date for becoming an effective drug for hypercholesterolemia therapy [8]. Its chemical structure is shown in Fig. 1. The empirical formula is $\mathrm{C}_{29} \mathrm{H}_{43} \mathrm{NO}_{2} \mathrm{~S}$, with a molecular weight of $469.73 \mathrm{~g} \mathrm{~mol}^{-1}$.

As a preliminary work, the influence of temperature and pressure on the solid solubility has been measured in pure $\mathrm{CO}_{2}$. Then, the solubility has been studied in $\mathrm{CO}_{2} /$ co-solvent mixtures. The choice of a co-solvent depends not only on its ability to enhance solubility but also on its availability in high purity, its physical and chemical characteristics. For pharmaceutical purposes, the co-solvent must be also non-toxic. A first screening of potential candidates led us to select ethanol and dimethylsulphoxide (DMSO).

\section{Experimental}

Equilibrium solubility data have been obtained by using a continuous flow apparatus, described previously [6]. Its flow sheet is shown in Fig. 2. The two liquid solvents (at room temperature and pumping pressure), carbon dioxide and one co-solvent (ethanol

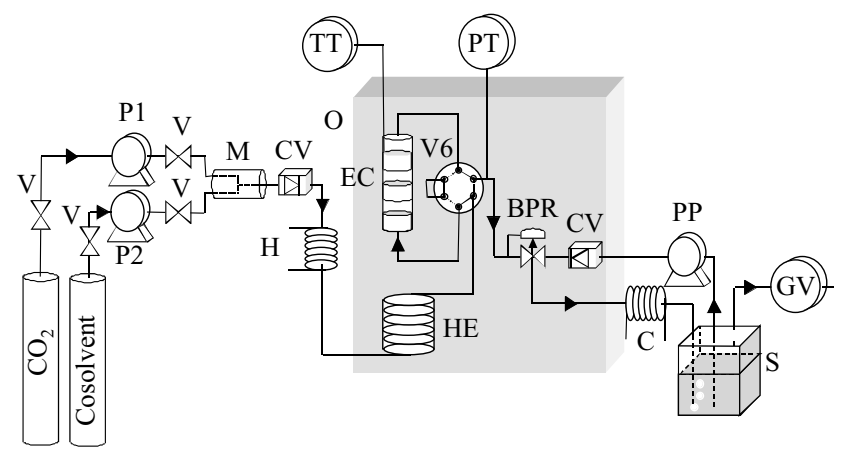

Fig. 2. Flow sheet of the apparatus for solubility measurements. V: 2 way valves; P1, P2: high pressure pumps; M: mixer; CV: checking valve; $\mathrm{H}$ : heater; $\mathrm{O}$ : thermostated oven; $\mathrm{HE}$ : heat exchanger; V6: 6 way-2 position valve; EC: equilibrium cell; TT: temperature transducer; PT: pressure transducer; BPR: back pressure regulator; C: cooler; S: separator; PP: peristaltic pump; GV: gas volumeter. 
or DMSO), are compressed by two high-pressure syringe pumps ( $\mathrm{P} 1$ and $\mathrm{P} 2)$ working at constant flow rates depending on the desired composition. A mixer (M) ensures that the two liquids are efficiently mixed. The homogeneous high-pressure liquid then passes through a heater $(\mathrm{H})$ used to rapidly heat the solvent to temperatures above its critical temperature. The supercritical fluid then enters an oven $(\mathrm{O})$ in which the solubility cell (EC) is located and is thermo-regulated to within $0.05 \mathrm{~K}$. The heat exchanger, $\mathrm{HE}$, placed in the oven, enables the solvent to reach the desired extraction temperature. Downstream of HE, a six-way two-position high-pressure valve is used to either direct the fluid to the cell or to bypass it. EC contains three cylindrical compartments placed one above the other, inside which the solid powder is packed. They are fitted at their bottom with stainless steel sintered disks to retain the solid and give good dispersion of the supercritical solvent. The temperature inside the cell is measured directly using a four-wire $100 \Omega$ platinum probe while the pressure is measured in the downstream line of the cell. The pressure of the supercritical phase is regulated downstream by means of a back pressure regulator (BPR), which maintains the upstream pressure constant to within $0.7 \%$ during the experiment, whilst the outlet of the BPR, is at atmospheric pressure. A recovery liquid solvent stream is circulated just at the outlet stream of the BPR to prevent solid deposits forming (clogging) and then to transfer all the solute, in a liquid state to a trap for reliable analysis. Finally, a separator (S) is used to vent off the gas and collect the solvent phase. The total volume of gaseous $\mathrm{CO}_{2}$ (extraction solvent) is measured by means of a gas volumeter $(\mathrm{GV})$ and the concentration of solid in the recovery liquid phase is obtained by analysis. The solubility $\left(y_{2}\right)$ of the solid in supercritical fluid can then be calculated from these two quantities and the total volume of the recovery liquid.

Measurements have been performed at various flow rates, to confirm that the phase flowing from the cell is saturated. The equilibrium conditions are guaranteed when the flow rate has no significant effect on the measured solubility values.

Eflucimibe was provided by Institut de Recherche Pierre Fabre (IRPF) as a white crystalline powder which purity, measured by high-performance liquid chromatography, is superior to 99\% [7]. For this molecule, a $\mathrm{CO}_{2}$ flow time of $45 \mathrm{~min}$ at $1 \mathrm{~cm}^{3} \mathrm{~min}^{-1}$ was sufficient to obtain solubility data reproducible to within 5\%. Ethanol was used as the recovery solvent. HPLC analyses conditions were the same with or without co-solvent (solid dissolved in pure ethanol or with a volume fraction of DMSO lower than 5\%). To verify that no solid residue remained in the recovery solvent line, the ethanol used for cleaning this line was carefully analysed after each experiment.

In addition, we have checked that solvents are really in supercritical state before entering the equilibrium cell. However, little $(P, T, y)$ data is available for the $\mathrm{CO}_{2}$-DMSO binary mixture. Only the data proposed by Kordikowski et al. [9] is sufficiently complete. The authors have fitted to their data the Peng-Robinson equation of state (PR EoS) [10] with two quadratic mixing rules that include two temperature independent binary interaction parameters, $k_{i j}$ and $l_{i j}$. As these authors provide also data for $\mathrm{CO}_{2}$-ethanol binary mixture, we have chosen to use their results to have parameters from the same origin for the two co-solvents. These coefficients are: $k_{i j}=0.089$ and $l_{i j}=0$ for the $\mathrm{CO}_{2}$-ethanol mixture; $k_{i j}=0.015$ and $l_{i j}=-0.025$ for the $\mathrm{CO}_{2}-\mathrm{DMSO}$ mixture.

\section{Results and discussion}

\subsection{Solubility in pure $\mathrm{CO}_{2}$}

The eflucimibe solubility $\left(y_{2}\right)$ was measured at 308.15 and $318.15 \mathrm{~K}$ (Table 1). It is noticeable that the values recorded are remarkably low, giving confirmation of the accuracy of the apparatus. The effect of pressure on the solute solubility follows the expected trends, the solubility increasing with pressure for the two temperatures studied. The density of $\mathrm{CO}_{2}$ increases with pressure, the mean intermolecular distance between $\mathrm{CO}_{2}$ molecules decreases, thereby increasing interaction between the solute and solvent molecules.

The existence of the crossover pressure is well known and illustrated in a number of experimental studies [11]. The pressure value where the solubility isotherms at various temperatures intersect each other, is the result of the competing effects of solute vapour pressure and solvent density. Indeed, with increasing temperature, the density decrease induces a solubility decrease, while the correlative vapour pressure in- 
Table 1

Eflucimibe solubility in supercritical $\mathrm{CO}_{2}$ at 308.15 and $318.15 \mathrm{~K}$

\begin{tabular}{|c|c|c|}
\hline$P(\mathrm{MPa})$ & $\rho_{1}\left(\mathrm{~kg} \mathrm{~m}^{-3}\right)^{\mathrm{a}}$ & $10^{7} \times y_{2}$ \\
\hline \multicolumn{3}{|c|}{$T=308.15 \mathrm{~K}$} \\
\hline 9.86 & 644 & 0.68 \\
\hline 10.35 & 667 & 0.74 \\
\hline 12.56 & 738 & 1.39 \\
\hline 15.35 & 796 & 2.35 \\
\hline 19.85 & 860 & 4.23 \\
\hline 22.28 & 887 & 4.96 \\
\hline 25.41 & 916 & 5.64 \\
\hline 27.46 & 933 & 5.71 \\
\hline 29.73 & 950 & 6.44 \\
\hline \multicolumn{3}{|c|}{$T=318.15 \mathrm{~K}$} \\
\hline 9.33 & 375 & 0.14 \\
\hline 9.92 & 447 & 0.27 \\
\hline 10.79 & 528 & 0.78 \\
\hline 12.01 & 601 & 1.17 \\
\hline 14.86 & 698 & 3.50 \\
\hline 15.08 & 704 & 3.59 \\
\hline 19.59 & 790 & 6.83 \\
\hline 20.20 & 799 & 7.38 \\
\hline 25.30 & 861 & 10.79 \\
\hline 25.55 & 863 & 11.18 \\
\hline 30.19 & 905 & 15.67 \\
\hline
\end{tabular}

a Calculated with the PR EoS [10].

crease leads to a solubility enhancement. At pressures below the crossover pressure, the density effect is dominant, thus the solubility decreases when temperature increases (retrograde vaporisation). Above the crossover pressure, the solute vapour pressure effect becomes predominant and the solubility increases with temperature. From Fig. 3, the crossover pressure can be estimated at about $10 \mathrm{MPa}$. Thus, over the

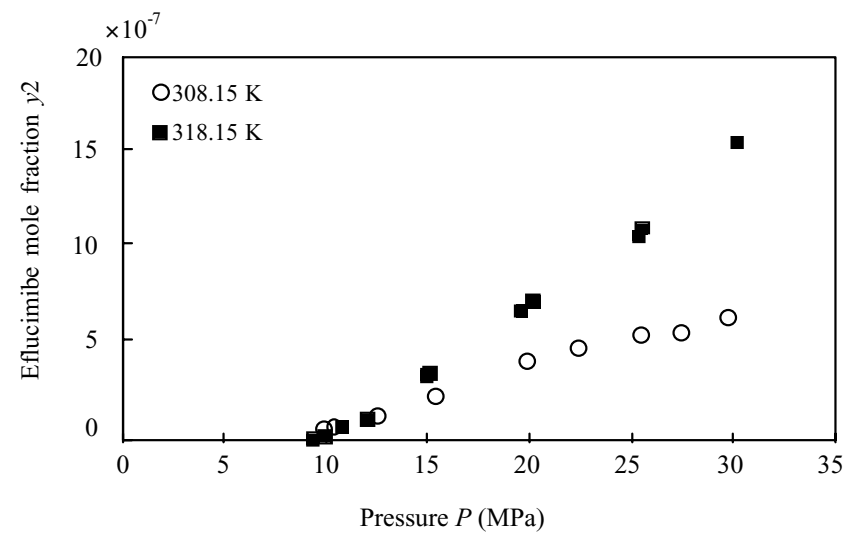

Fig. 3. Solubility of eflucimibe in pure supercritical $\mathrm{CO}_{2}$ vs. pressure at 308.15 and $318.15 \mathrm{~K}$.
Table 2

Eflucimibe solubility at $318.15 \mathrm{~K}$ and at constant co-solvent mole fraction vs. pressure

\begin{tabular}{llc}
\hline$P(\mathrm{MPa})$ & $\rho_{\mathrm{f}}\left(\mathrm{kg} \mathrm{m}^{-3}\right)^{\mathrm{a}}$ & $10^{7} \times y_{2}$ \\
\hline Ethanol $\left(y_{3}=0.05\right)$ & & \\
9.80 & 647.6 & 11.09 \\
9.95 & 653.5 & 12.03 \\
12.25 & 720.8 & 20.43 \\
12.27 & 721.2 & 20.87 \\
14.80 & 769.9 & 29.31 \\
14.90 & 771.6 & 30.98 \\
17.45 & 808.2 & 48.37 \\
22.40 & 861.9 & 72.81 \\
27.17 & 901.1 & 88.20 \\
29.69 & 918.7 & 90.82 \\
30.36 & 923.1 & 90.75 \\
DMSO $\left(y_{3}=0.02\right)$ & & \\
12.25 & 704.3 & 32.84 \\
14.97 & 760.3 & 72.25 \\
17.17 & 794.2 & 113.84 \\
20.10 & 830.4 & 152.34 \\
26.76 & 891.8 & 282.59 \\
29.11 & 909.2 & 365.37 \\
\hline a Calculated with the PR EoS [10] and binary interaction pa-
\end{tabular}

rameters from the work of Kordikowski et al. [9].

pressure range investigated here, we can consider that solubility is an increasing function of temperature.

\subsection{Ethanol and DMSO co-solvent effects}

Two series of measurements have been performed. The first concerns the influence of $P$ on $y_{2}$, at constant $T$ and constant co-solvent mole fraction $y_{3}$. The solubility has been measured at $318.15 \mathrm{~K}$ for different pressures with $y_{3}=0.05$ for ethanol and $y_{3}=0.02$ for DMSO (Table 2).

The second series of measurements involved the variation of $y_{2}$, as a function of $y_{3}$ at constant $P$ and $T$. The solubility at $318.15 \mathrm{~K}$ and $20 \mathrm{MPa}$ has been measured for different mole fractions of the two co-solvents (Table 3 ).

To better illustrate the solubility enhancement, a co-solvent effect $A_{\mathrm{c}}$ is defined as the ratio of the solubility obtained with co-solvent, $y_{2}\left(P, T, y_{3}\right)$, to that obtained without co-solvent at the same temperature and pressure, $y_{2}\left(P, T, y_{3}=0\right)$ :

$A_{\mathrm{c}}\left(P, T, y_{3}\right)=\frac{y_{2}\left(P, T, y_{3}\right)}{y_{2}\left(P, T, y_{3}=0\right)}$ 
Table 3

Eflucimibe solubility at $318.15 \mathrm{~K}$ and $20 \mathrm{MPa}$ vs. co-solvent mole fraction

\begin{tabular}{rlr}
\hline \multicolumn{1}{l}{$y_{3}$} & $\rho_{\mathrm{f}}\left(\mathrm{kg} \mathrm{m}^{-3}\right)^{\mathrm{a}}$ & $10^{7} \times y_{2}$ \\
\hline Ethanol & & \\
4.0 & 830.8 & 34.6 \\
7.6 & 854.5 & 144.2 \\
7.7 & 855.1 & 143.1 \\
10.2 & 868.1 & 285.9 \\
16.2 & 889.5 & 737.4 \\
17.1 & 891.7 & 802.7 \\
DMSO & & \\
0.9 & 813.0 & 21.0 \\
1.3 & 819.4 & 51.9 \\
2.0 & 829.3 & 110.7 \\
2.1 & 830.6 & 152.3 \\
2.6 & 836.8 & 299.8 \\
2.7 & 838.0 & 343.3 \\
3.3 & 844.4 & 469.0 \\
\hline
\end{tabular}

${ }^{\text {a }}$ Calculated with the PR EoS [10] and binary interaction parameters from Kordikowski et al. [9].

At $318.15 \mathrm{~K}, A_{\mathrm{c}}$ has been plotted versus $P$ (Fig. 4) and versus $y_{3}$ (Fig. 5). From these figures, it is clear that the solubility is increased by both co-solvents, with however a higher increase with DMSO. For instance, at $20 \mathrm{MPa}$ and $318.15 \mathrm{~K}$, the solubility is ten times higher with either $6 \%$ of ethanol or $2 \%$ of DMSO, and is multiplied by a factor 50 for about $11 \%$ of ethanol or $3 \%$ of DMSO in the solvent. This solubility enhancement can be attributed to three possible effects: increased density of the fluid mixture, modifications in phase equilibria and specific interactions between the solute and co-solvent.

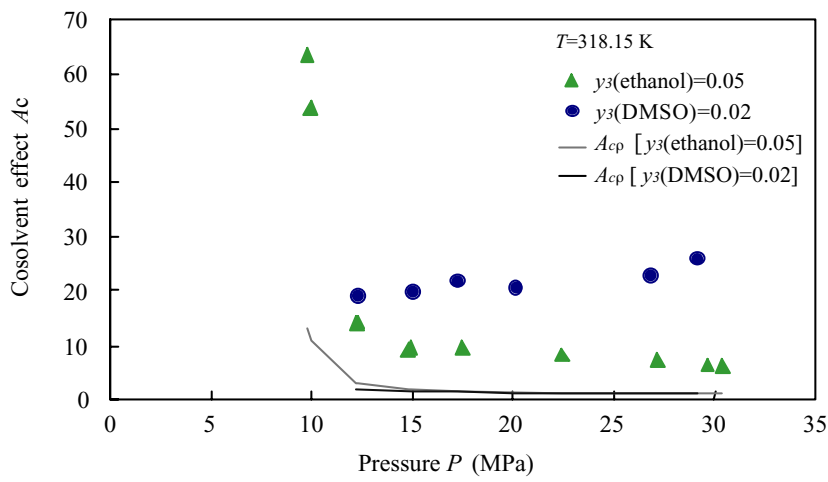

Fig. 4. The co-solvent effect in supercritical co-solvent- $\mathrm{CO}_{2}$ mixtures vs. pressure at $318.15 \mathrm{~K}$ and constant co-solvent mole fraction.

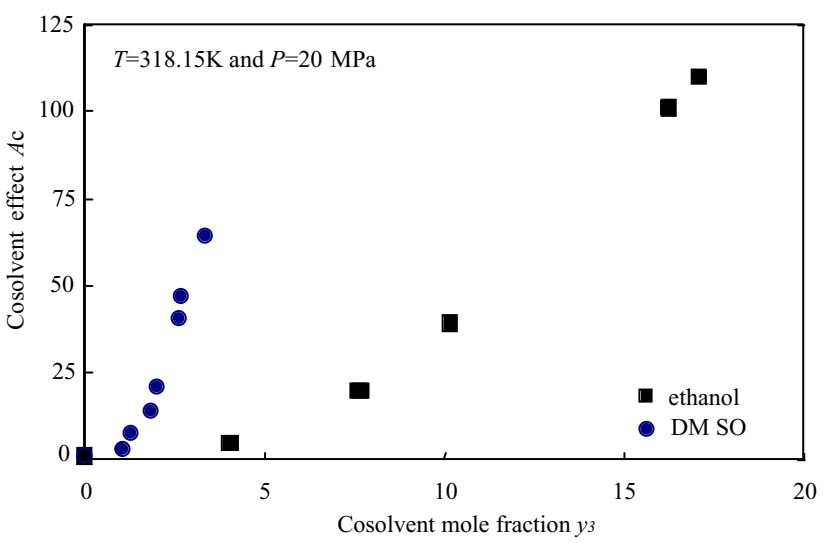

Fig. 5. The co-solvent effect in supercritical co-solvent- $\mathrm{CO}_{2}$ mixtures vs. co-solvent mole fraction at $318.15 \mathrm{~K}$ and $20 \mathrm{MPa}$.

The density contribution to the co-solvent effect is estimated by calculating a co-solvent density effect, $A_{\mathrm{c} \rho}$, defined as follows:

$A_{\mathrm{c} \rho}\left(P, T, y_{3}\right)=\frac{y_{2}\left(P, T, \rho_{\mathrm{f}}, y_{3}=0\right)}{y_{2}\left(P, T, \rho_{\mathrm{CO}_{2}}, y_{3}=0\right)}$

$A_{\mathrm{c} \rho}\left(P, T, y_{3}\right)$ is the co-solvent density effect at $P, T$ and $y_{3}$. It compares the solubility of the solid in pure $\mathrm{CO}_{2}$ at $T$ and $P, y_{2}\left(P, T, \rho_{\mathrm{CO}_{2}}, y_{3}=0\right)$, to that also in pure $\mathrm{CO}_{2}$ at the same temperature and pressure but at the density of the mixtures $\rho_{\mathrm{f}}$ with a co-solvent mole fraction $y_{3}, y_{2}\left(P, T, \rho_{\mathrm{f}}, y_{3}=0\right)$. The co-solvent density effect is represented in Fig. 4. It is clear that co-solvent effects cannot be attributed to a density effect alone, neither for ethanol nor for DMSO.

The presence of a co-solvent in a SCF can enhance the melting point depression of a solid solute in a SCF. This effect is usually accompanied by a reduction of the upper critical end point (UCEP) pressure of the system [12]. This effect is important due to the drastic enhancement of the solute solubility in the vicinity of the UCEP [13]. Unfortunately, the contribution of this effect to the observed co-solvent effect is difficult to estimate because the relevant three phase solid-liquid-gas coexistence curves are not available. However, a qualitative indication of the importance of this effect can be obtained from the examination of the solubility isotherms [14]. When conditions are close to the UCEP, the slope of the solubility isotherms, $\partial y_{2} / \partial P$, becomes relatively large. An inspection of our solubility isotherms in Fig. 6 reveals that as pressure increases, no dramatic variation of $\partial y_{2} / \partial P$ occurs. It 


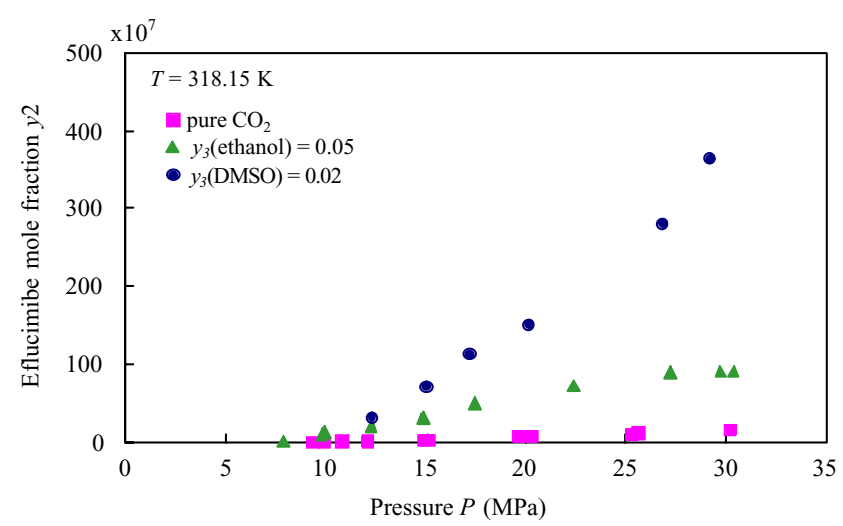

Fig. 6. Solubility of eflucimibe in supercritical co-solvent- $\mathrm{CO}_{2}$ mixtures vs. pressure at $318.15 \mathrm{~K}$ and at constant co-solvent mole fraction.

may be concluded that co-solvent effects are the result of factors more significant than the proximity of the operating conditions to the UCEP.

\subsection{The influence of solubility parameters on co-solvent effect}

The minor contribution of density to the co-solvent effect suggests that chemical forces, rather than physical forces, are responsible for the obtained solubility enhancement. These chemical forces are represented by specific interactions between the solute and the co-solvent. Several authors have observed a linear dependence of $A_{\mathrm{c}}$ with the co-solvent concentration $[15,16]$. However, in our experiments, $A_{\mathrm{c}}$ is not a linear function of $y_{3}$, the co-solvent effect increasing more rapidly for higher mole fractions (Fig. 5). This different behaviour may be indicative of higher order interactions between the solute and the co-solvent. The type of interaction can be discussed qualitatively on the basis of pure component properties as, for instance, solubility parameters [17]. Several solubility parameters are listed in Table 4 for the two co-solvents and for compounds having the same functional groups as eflucimibe [18]. The total solubility parameter, $\delta_{\mathrm{T}}$, is the standard Hildebrand one. It is calculated by taking the ratio of the heat of vaporisation over the liquid volume. The parameters listed in Table 4 describe dispersion $\left(\delta_{\mathrm{D}}\right)$, orientation or permanent dipoles forces $\left(\delta_{\mathrm{O}}\right)$, induction forces $\left(\delta_{\mathrm{I}}\right)$, acidity $\left(\delta_{\mathrm{A}}\right)$, and basicity $\left(\delta_{\mathrm{B}}\right)$. Dispersive forces $\left(\delta_{\mathrm{D}}\right)$ are common to the interactions of all molecules whether or not they possess
Table 4

Solubility parameters (in $(\mathrm{MPa})^{1 / 2}$ ) for several compounds

\begin{tabular}{lllrllr}
\hline Compound & $\delta_{\mathrm{T}}$ & \multicolumn{1}{c}{$\delta_{\mathrm{D}}$} & \multicolumn{1}{c}{$\delta_{\mathrm{O}}$} & $\delta_{\mathrm{I}}$ & \multicolumn{1}{c}{$\delta_{\mathrm{A}}$} & \multicolumn{1}{c}{$\delta_{\mathrm{B}}$} \\
\hline Ethanol & 26.0 & 13.6 & 7.0 & 1.0 & 14.1 & 14.1 \\
DMSO & 24.6 & 17.2 & 12.5 & 4.3 & - & 10.6 \\
Acetone & 19.6 & 13.9 & 10.4 & 3.1 & - & 6.1 \\
Phenol & 24.8 & 19.4 & 4.7 & 0.8 & 19.0 & 4.7 \\
Diethyl sulphur & 17.6 & 16.8 & 3.5 & 0.5 & - & 5.3 \\
Propylamine & 18.2 & 14.9 & 3.5 & 0.4 & 3.7 & 11.3 \\
\hline
\end{tabular}

Data from Karger et al. [18].

a permanent dipole moment, and are the only interacting forces for non-polar solutes. Polar molecules are capable of both orientation interactions $\left(\delta_{\mathrm{O}}\right)$ and dipole induction $\left(\delta_{\mathrm{I}}\right)$. Acidity $\left(\delta_{\mathrm{A}}\right)$ and basicity $\left(\delta_{\mathrm{B}}\right)$ are a measure of the ability of a species to act as a proton donor or acceptor, respectively, for hydrogen bonding.

Ethanol is polar and shows a high capacity to form hydrogen bonds, being both a proton donor and acceptor (amphiprotic). DMSO is very polar, aprotic but shows a basicity close to that of ethanol.

To identify the potential interactions with the various groups of eflucimibe, co-solvent effects from literature have been examined for compounds characteristic of these groups. However, little data being available for DMSO, we have focused on the co-solvent effect of acetone, which presents some similar properties: it is polar, aprotic and basic. Finally, we have chosen results from Ekart et al. [15], who have studied effects of several co-solvents in ethane, in the following experimental conditions: $20 \mathrm{MPa}$ and $323 \mathrm{~K}$ with $y_{3}=$ 0.028 for ethanol and 0.038 for acetone (Table 5). A first comparison is made between fluorene, carbazole (substitution on fluorene of a $\mathrm{CH}_{2}$ group by a $\mathrm{NH}$

Table 5

The co-solvent effect of ethanol and acetone at $323 \mathrm{~K}$ and $20 \mathrm{MPa}$ on the solubility of various compounds in supercritical carbon dioxide

\begin{tabular}{lll}
\hline Compound & $\begin{array}{l}\text { Ethanol } \\
\left(y_{3}=0.028\right)\end{array}$ & $\begin{array}{l}\text { Acetone } \\
\left(y_{3}=0.038\right)\end{array}$ \\
\hline Fluorene & 1.13 & 1.44 \\
Carbazole & 2.27 & 2.27 \\
Fluorenone & 1.22 & 1.44 \\
Anthracene & 1.11 & 1.22 \\
2-Naphthol & 5.66 & 4.15 \\
\hline
\end{tabular}

Data from Ekart et al. [15]. 
amine group) and fluorenone (substitution on fluorene of a $\mathrm{CH}_{2}$ group by a $\mathrm{C}=\mathrm{O}$ ketone group). In the case of fluorene, which presents a weak dipolar moment, ethanol provokes a co-solvent effect of 1.13 and acetone, an effect of 1.44. In the case of fluorenone, a proton acceptor, the co-solvent effect is increased to up to 1.22 for ethanol and remains constant at 1.44 for acetone. However, carbazole exhibits a higher co-solvent effect of 2.27 for ethanol and acetone. The authors explain this observation by the ability of $\mathrm{N}-\mathrm{H}$ group to provide a proton, although propylamine only shows a low acidity. The second example compares non-polar anthracene and 2-naphthol, which corresponds to the substitution of an $\mathrm{H}$ atom by an $\mathrm{OH}$ phenol group on naphthalene, similar to anthracene. The co-solvent effect in the case of anthracene is 1.11 for ethanol and 1.22 for acetone. For 2-naphthol, the co-solvent effect is increased up to 5.66 for ethanol and 4.15 for acetone. The very acid phenol group interacts strongly with both the basic acetone and ethanol by means of hydrogen bonds. In the case of DMSO, the co-solvent effect should be higher than with acetone, due to a higher basicity. Moreover, DMSO is able to form 1:1 complexes with phenol [19]. The sulphur group is not treated in this work, but it does not seem able to noticeable interactions with the two co-solvents studied (see diethyl sulphur in Table 4). Moreover, this group is not able to form strong hydrogen bonds [20].

Finally, it seems that the amine and especially the phenol groups play a major role in the solubility increase of eflucimibe, by means of hydrogen bonds. However, despite its higher basicity, ethanol displays a lower co-solvent effect. Clearly, co-solvent basicity is not sufficient to explain the results, thus the dispersion parameter $\left(\delta_{\mathrm{D}}\right)$, which is higher for DMSO should be also considered [17]. The lower co-solvent effect of ethanol might also be explained by the self-association between amphiprotic ethanol molecules, which are no longer available to interact with the solute molecules.

Another observation can be made about the influence of $P$ on $A_{\mathrm{c}}$ (Fig. 4), which is opposite for ethanol and DMSO, the co-solvent effect decreasing with pressure for ethanol and increasing for DMSO. Specific interactions cause the formation of clusters with molecules of solute, solvent and co-solvent, and thus the region around the solute molecule is enriched with co-solvent. This local composition can be several times greater than that of the bulk composition.
However, the importance of this local ordering of co-solvent (and thus co-solvent effect) decreases with increasing pressure, and at pressures high enough, the concentration of the co-solvent around the solute approaches the bulk concentration [5]. While the local composition enhancement decreases, the bulk concentration of co-solvent (and thus solubility) always increases with increasing pressure, due to the increase in density. On the basis of these elements, it has been observed that, at low co-solvent concentration, the co-solvent effect depends predominantly on the bulk concentration of co-solvent around the solute, and as the co-solvent concentration is increased, the effect of local concentration enhancement becomes significant [21]. In our study, the mixture with an ethanol mole fraction of 0.05 corresponds to a high concentration. In this case, the influence of local co-solvent concentration is predominant, and the co-solvent effect decreases with pressure (Fig. 4). As the local composition enhancement is maximised in the region of high compressibility, the decrease in the difference between bulk and local co-solvent concentrations leads to the observed decrease with pressure [21]. With DMSO, the co-solvent mole fraction is lower and the predominant effect is that of bulk concentration. As this concentration increases with the fluid density, the co-solvent effect slowly increases with pressure in the studied range.

\section{Conclusion}

The solubility behaviour of eflucimibe was studied in pure supercritical carbon dioxide at 308 and $318 \mathrm{~K}$ between 8 and $30 \mathrm{MPa}$. The solubility appeared to be an increasing function of both pressure and temperature but remained at very low levels.

The effect of two co-solvents, ethanol and DMSO, was then investigated. The solubility was found to be enhanced by both co-solvents, with however a higher increase with DMSO. The co-solvent effect was found to vary nonlinearly with the co-solvent concentration, showing the importance of specific interactions between the co-solvents and the solute in comparison with density effect. These interactions could qualitatively be explained by means of solubility parameters of co-solvents and of solid functional groups. Finally, hydrogen bonds seem to play the most important role 
in solubility enhancement. It was then observed that the level of the co-solvent mole fraction determines the variation of the co-solvent effect with pressure. At low co-solvent mole fraction, the co-solvent effect slowly increases with increasing pressure while for higher values, the co-solvent effect decreases with increasing pressure.

To extend these results, modelling is necessary to provide a tool for prediction of solid solubilities in supercritical mixtures. Recently, we have proposed a generalised density-based model [22], in which effects of density, temperature and co-solvent composition are quantified.

\section{Acknowledgements}

The authors acknowledge the Institut de Recherche Pierre Fabre (IRPF) Company for providing eflucimibe and for financial and technical support.

\section{References}

[1] J. Jung, M. Perrut, Particle design using supercritical fluids: literature and patent survey, J. Supercrit. Fluids 20 (2001) 179-219.

[2] C. Eckert, D. Ziger, K.P. Johnston, S. Kim, Solute partial molal volumes in supercritical fluids, J. Phys. Chem. 90 (1986) 2738-2746.

[3] P.G. Debenedetti, Clustering in dilute, binary, supercritical fluid mixtures: a fluctuation analysis, Chem. Eng. Sci. 42 (1987) 2203-2212.

[4] S. Kim, K.P. Johnston, Clustering in supercritical fluid mixtures, AIChE J. 33 (1987) 1603-1611.

[5] C. Yonker, R. Smith, Solvatochromic behavior of binary supercritical fluids: the carbon dioxide/2-propanol system, J. Phys. Chem. 92 (1988) 2374-2378.

[6] M. Sauceau, J. Fages, J.-J. Letourneau, D. Richon, A novel apparatus for accurate measurements of solid solubilities in supercritical phases, Ind. Eng. Chem. Res. 39 (2000) 46094614.

[7] J.-P. Ribet, R. Pena, A. Chauvet, J.-F. Patoiseau, J.-M. Autin, R. Segonds, M. Basquin, J.M. Autret, Polymorphisme cristallin de l'eflucimibe, Ann. Pharm. Fr. 60 (2002) 177-186.
[8] D. Junquero, F. Bruniquel, X. N'Guyen, J.-M. Autin, J.-F. Patoiseau, A.-D. Degryse, F.C. Colpaert, A. Delhon, F 12511, a novel ACAT inhibitor, and atorvastatin regulate endogenous hypercholesterolemia in a synergistic manner in New Zealand rabbits fed a casein-enriched diet, Atherosclerosis 155 (2001) $131-142$

[9] A. Kordikowski, A.P. Schenk, R.M. Van Nielen, C.J. Peters, Volume expansions and vapor-liquid equilibria of binary mixtures of a variety of polar solvents and certain near-critical solvent, J. Supercrit. Fluids 8 (1995) 205-216.

[10] D.-Y. Peng, D. Robinson, A new two-constant equation of state, Ind. Eng. Chem. Fundam. 15 (1976) 59-64.

[11] N. Foster, G. Gurdial, J. Yun, K. Liong, K. Tilly, K. Ting, H. Singh, J. Lee, Significance of the crossover pressure in solid-supercritical fluid phase equilibria, Ind. Eng. Chem. Res. 30 (1991) 1955-1964.

[12] R. Lemert, K.P. Johnston, Solubilities and selectivities in supercritical fluid mixtures near critical end points, Fluid Phase Equilib. 59 (1990) 31-55.

[13] M. McHugh, V. Krukonis, Supercritical Fluid Extraction: Principles and Practice, 2nd ed., Butterworths, Boston, 1994.

[14] C. Saquing, F. Lucien, N. Foster, Steric effects and preferential interactions in supercritical carbon dioxide, Ind. Eng. Chem. Res. 37 (1998) 4190-4197.

[15] M. Ekart, K. Bennett, S. Ekart, G. Gurdial, C. Liotta, C. Eckert, Cosolvent interactions in supercritical fluid solutions, AIChE J. 39 (1993) 235-248.

[16] N. Foster, H. Singh, J. Yun, D. Tomasko, S. Macnaughton, Polar and nonpolar cosolvent effects on the solubility of cholesterol in supercritical fluids, Ind. Eng. Chem. Res. 32 (1993) 2849-2853.

[17] J. Dobbs, J. Wong, R. Lahiere, K.P. Johnston, Modification of supercritical fluid phase behavior using polar cosolvents, Ind. Eng. Chem. Res. 26 (1987) 56-65.

[18] B. Karger, L. Snyder, C. Eon, An expanded solubility parameter treatment for classification and use of chromatographic solvents and adsorbents-parameters for dispersion, dipole and hydrogen bonding interactions, J. Chromatogr. 125 (1976) 71-88.

[19] H. Mark, D. Othmer, C. Overberger, G. Seaborg, Kirk-Othmer, Encyclopedia of Chemical Technology, vol. 22, 3rd ed., Wiley/Interscience, New York, 1983.

[20] K. Vollhardt, Traité de chimie organique, Editions De Boeck-Wesmael, Bruxelles, 1990.

[21] S. Kim, K.P. Johnston, Clustering in supercritical fluid mixtures, AIChE J. 33 (1987) 1603-1611.

[22] M. Sauceau, J.-J. Letourneau, D. Richon, J. Fages, Enhanced density-based models for solid compound solubilities in supercritical carbon dioxide with cosolvents, Fluid Phase Equilib. 208 (2003) 99-113. 